\title{
Síndrome de Cornélia de Lange e Doença de Graves: uma associação rara
}

\section{Cornelia de Lange Syndrom and Graves disease: a rare association}

Tássia Calvet Pinto Ferreira ${ }^{1}$ (orcid.org/0000-0002-6812-8807), Airton Afonso Ferreira Rebelo², Amanda Machado Kahwage $^{1,3}$, Ryssia de Oliveira Braun Guimarães ${ }^{4}$

1. Hospital Ophir Loyola (HOL), Belém, PA, Brasil. 2. Faculdade de Medicina pela Universidade do Estado do Pará (UEPA), Belém, PA, Brasil. 3. Pós-graduanda em Medicina Tropical pela Universidade Federal do Pará (UEPA), Belém, PA, Brasil. 4. Pós-graduanda em Educação Médica pelo Centro Universitário do Estado do Pará (CESUPA), Belém, PA, Brasil.

\section{Resumo}

Introdução: A síndrome de Cornelia de Lange (SCdL) corresponde a uma condição rara caracterizada por mutações nos genes responsáveis pelas proteínas estruturais e reguladoras do complexo da coesina, levando o paciente à distrofia facial e aos atrasos no crescimento e desenvolvimento. Seu diagnóstico é baseado nos achados clínicos e/ou a identificação da heterozigose patogênica variante em N1PBL, RAD21, ou SMC3 ou homozigose patogênica variante em HDAC8 ou SMC1A. Essa síndrome possui um amplo espectro de manifestações que incluem anormalidades neurológicas, endocrinológicas, musculoesqueléticas e cutâneas. A Doença de Graves, por sua vez, representa o expoente mais comum de hipertireodismo, possui origem autoimune e resulta de uma complexa interação entre fatores genéticos e ambientais. Relato de caso: Este artigo tem por objetivo relatar um caso de uma paciente de 22 anos com diagnóstico de SCdL, a qual abriu o quadro de hipertireoidismo por Doença de Graves, apresentando insônia, irritabilidade e agitação, com melhora após tratamento medicamentoso.

Palavras-chave: Hipertireoidismo. Síndrome de Cornélia de Lange. Doença de Graves.

\begin{abstract}
Introduction: The Cornelia de Lange syndrome is a rare condition characterized by mutations in genes responsible for structural and regulatory proteins of the coesin complex, causing facial dystrophy, delays in development and growth. Your Diagnosis is based on clinical findings and/or the identification of a heterozygous pathogenic variant in NIPBL, RAD21 and SMC3 or a hemizyous pathogenic variant in HDAC8 or SMC1A. This syndrome has a wide spectrum of manifestations that includes neurological, endocrinological, muscle-skeletal and cutaneous abnormalities. Graves' disease, in turn, represents the most common etiology of hyperthyroidism; it has an autoimmune origin and results from a complex interaction between genetic and environmental factors. Case report: Therefore, the current study aims to report a case of a 22-year-old female with diagnosis of Graves' disease, presenting insomnia, irritability and restlessness with improvement after drug treatment.
\end{abstract}

Keywords: Hyperthyroidism. Cornelia de Lange Syndrome. Graves' disease

\section{INTRODUÇÃO}

A síndrome de Cornélia de Lange ( $\mathrm{SCdL}$ ) é uma condição causada por mutações nos genes responsáveis pelas proteínas estruturais e reguladoras do complexo da coesina, incluindo NIPBL, SMC1A, HDAC8, SMC3 e RAD21, levando o paciente à distrofia facial e ao atraso no crescimento e desenvolvimento. A doença apresenta uma incidência mínima estimada de 1:10.000 nascidos vivos ${ }^{1}$. A maioria dos casos encontrados é esporádica, mas foram relatados casos familiares com transmissão vertical, sugerindo herança autossômica dominante, relacionando-se aos genes NIPBL, RAD21 e SMC3, assim como herdados ligados ao cromossomo $\mathrm{X}$, relacionando-se aos genes HDAC8 e SMC1A ${ }^{2}$.

Os achados frequentes incluem micrognatia mandibular, sinofris, microcefalia, estreitamento parieto-parietal, micrognatia, surdez, tórax cilíndrico, defeitos do septo cardíaco, disfunção gastrointestinal, perda auditiva, miopia e criptorquidismo ou genitália hipoplásica, além de agitação psicomotora e alterações comportamentais. Observa-se, também, encurtamento de mãos e pés, sindactilia e implantação alta do polegar. Os indivíduos, com um fenótipo mais ameno, têm crescimento menos grave, cognitivo e envolvimento dos membros, mas geralmente possuem características faciais consistentes com SCdL $2,3,4$.

O hipertireoidismo consiste em um estado hipermetabólico causado pelo aumento da função da glândula tireoide e consequente aumento dos níveis circulantes dos hormônios T3 e T4, associado à supressão do $\mathrm{TSH}^{5}$. A Doença de Graves é o protótipo de tal condição: anormalidade autoimune que se origina da produção pelos linfócitos $B$ de anticorpos contra o TSHR (TRAb)6. Perda de peso, agitação, insônia, fadiga, intolerância ao calor, tremores e palpitações são os sintomas mais comuns ${ }^{7}$.

\section{RELATO DO CASO}

Paciente, S.P.L.S, do sexo feminino, 22 anos, natural e residente de Belém-PA, foi avaliada no ambulatório de Endocrinologia do Centro Hospitalar Jean Bitar - Pará, em março de 2015, encaminhada pela geneticista para avaliação devido à agitação psicomotora e à insônia há 4 meses. A mãe negava outros

Correspondência: Tássia Calvet Pinto Ferreira. Av. Gov Magalhães Barata, 992 - São Brás, Belém - PA, 66060-281, Brasil. e-mail: tassiacalvet@gmail.com Conflito de interesse: Não há conflito de interesse por parte de qualquer um dos autores.

Recebido em: 28 Jun 2017; Revisado em: 7 Dez 2017; 9 Fev 2018. Aceito em: 17 Fev 2018 
sintomas. Paciente com diagnóstico prévio de síndrome de Cornélia de Lange, doença do refluxo gastroesofágico e gastrite crônica. Antecedentes mórbidos familiares: ausência de história de doença tireoidiana ou doenças autoimunes na família.

Ao exame, encontrava-se em bom estado geral, com características faciais típicas da $\mathrm{SCdL}$, com sinofre, ponte nasal baixa, narinas antevertidas, lábio superior fino, baixa implantação dos cabelos e das orelhas, prognatismo maxilar e micrognatia (Figura 1). Frequência cardíaca: $136 \mathrm{bpm}$; pressão arterial de $110 \times 70 \mathrm{mmHg}$. Ausculta cardiorrespiratória e abdome sem anormalidades. Peso: 27,300kg; Altura:1,20m, IMC:18,95.

A Semiologia específica evidenciou a tireoide palpável, com consistência fibroelástica, volume discretamente aumentado difusamente, sem presença de nódulos e linfonodomegalia. Exames laboratoriais foram solicitados, e os resultados podem ser observados no Quadro 1. A ultrassonografia com Doppler da tireoide revelou: órgão na topografia habitual; lobos direito e esquerdo com textura heterogênea com múltiplos focos hipoecoicos de permeio, contornos labutados, limites imprecisos, com vascularização discretamente aumentada, sem imagens nodulares. No aspecto geral, glândula de dimensão acrescida. Peso:18g. (Figura 2).

Foi iniciado Metimazol 20mg uma vez ao dia, após diagnóstico de hipertireoidismo primário por Doença de Graves. Retornou para consulta após dois meses com resultado de novos exames (Quadro 1), ajustando-se a dose para $10 \mathrm{mg}$ uma vez ao dia. A paciente apresentou urticária, sendo orientada a substituição da medicação para o Propiltiouracil 100mg uma vez ao dia e iniciado o uso de anti-histamínico por cinco dias com remissão completa do quadro. Finalmente, houve melhora da agitação psicomotora, da insônia e ganho ponderal de cerca de 3 kg após estabilização da dose deste último fármaco. Devido ao quadro de retardo mental importante, optou-se por não indicar iodoterapia pela necessidade de isolamento temporário da paciente.

Figura 1. Características faciais típicas da síndrome. A - Lábio superior fino. B - Baixa implantação da orelha e cabelo

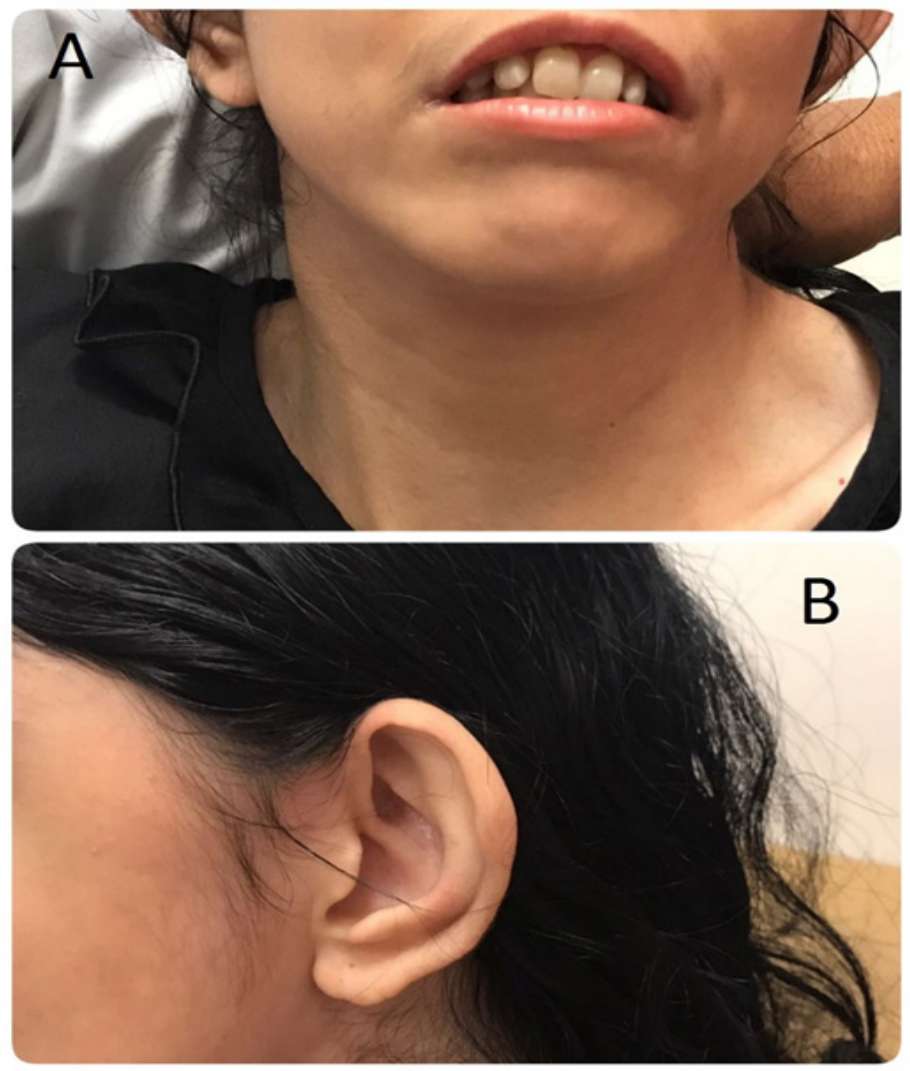

Quadro 1. Exames laboratoriais realizados pelo paciente durante o período de acompanhamento ambulatorial.

\begin{tabular}{llllll}
\hline Datas & $\mathbf{1 3 / 3 / 1 5}$ & $\mathbf{2 3 / 5 / 1 5}$ & $\mathbf{4 / 8 / 1 5}$ & $\mathbf{4 / 6 / 1 6}$ & $\mathbf{2 0 / 1 0 / 1 6}$ \\
\hline TSH & $0,15 \mathrm{mU} / \mathrm{L}$ & $5,29 \mathrm{mU} / \mathrm{L}$ & $0,97 \mathrm{mU} / \mathrm{L}$ & $1,98 \mathrm{mU} / \mathrm{L}$ & $0,9 \mathrm{mU} / \mathrm{L}$ \\
T4L & $2,35 \mathrm{mU} / \mathrm{L}$ & $0,79 \mathrm{mU} / \mathrm{L}$ & $1,17 \mathrm{mU} / \mathrm{L}$ & $1,38 \mathrm{mU} / \mathrm{L}$ & $1,35 \mathrm{mU} / \mathrm{L}$ \\
ANTI-TPO & Negativo & & & & \\
TRAB & 3,87 & & & & \\
ANTI-TG & Negativo & & & & \\
\hline
\end{tabular}


Figure 2. Ultrassonografia com Doppler da tireoide. A - Contornos labutados com vascularização discretamente aumentada. B Textura heterogênea com múltiplos focos hipoecoicos de permeio.
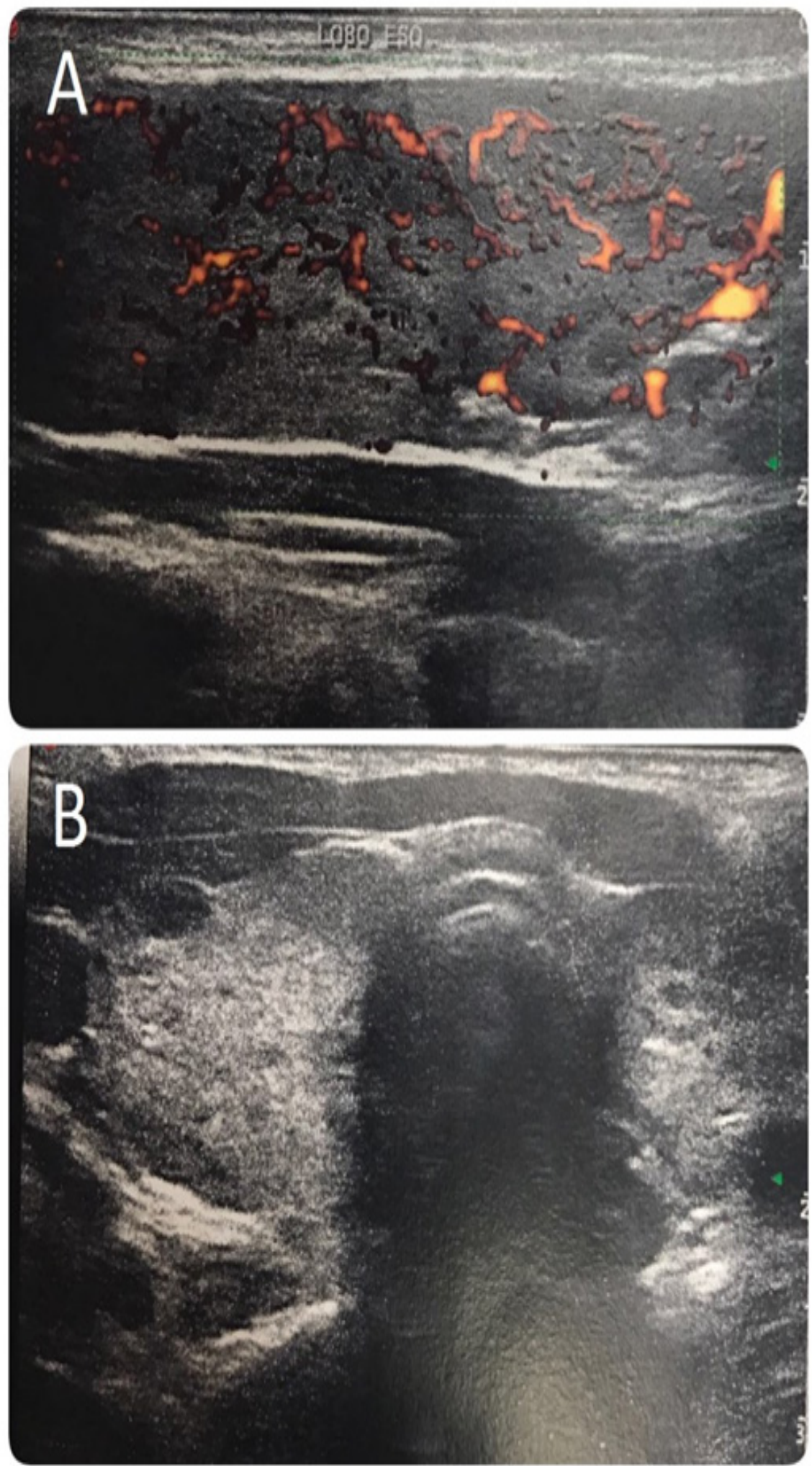


\section{DISCUSSÃO}

A SLdC é caracterizada por um amplo espectro fenotípico, entre os quais carcterísticas craniofaciais distintivas, retardo do crescimento, hirsutismo e defeitos de redução de membros superiores que variam de anormalidades falangeas sutis a oligodactilias. Mikołajewska (2013)9, em sua revisão, propôs um sistema de classificação da SCdL baseado na expressão fenotípica, dividindo em: tipo 1 (com as alterações faciais e esqueléticas características), assemelhando-se ao quadro clínico da paciente. Tipo 2 (com as alterações faciais e esqueléticas características leves) e tipo 3, também chamado de SCdL-like, com expressão fenotípica semelhante, mas relacionada a afecções cromossômicas ou teratogênicas. Segundo o mesmo estudo, o diagnóstico se confirma se houver mutação em um dos genes envolvidos, características faciais e dois critérios de crescimento, desenvolvimento ou comportamentais, características faciais e um critério de crescimento, desenvolvimento ou comportamental, associados a dois critérios adicionais.

A paciente apresenta alterações faciais e ósseas, típicas da síndrome, bemcomoexibeimportantedificuldadenoaprendizado escolar e ataxia, o que denota um déficit neuropsicomotor generalizado. Esse fato reforça que o diagnóstico da síndrome é eminentemente clínico e fenotípico10. Muitos indivíduos demonstram tendências autistas e autodestrutivas. A paciente apresentava episódios de agressividade e irritabilidade durante as consultas. Tal constatação está em concordância com Ellaithi et al (2007)8, que descrevem que é comum indivíduos com a $\mathrm{SCdL}$ apresentarem tendência à agressão e às características de autismo.

Nisihara et al (2006)11 relataram uma incidência de hipotireoidismo maior em pessoas com síndromes dismórficas. Entretanto, os sintomas da hipofunção da glândula tireoide podem ser mascarados pelo próprio quadro clínico sindrômico do paciente. Portanto, tal acometimento deve ser rastreado com maior frequência e, de preferência, ainda na infância, período em que a doença traz maiores complicações.

Silva e Sandrini (2013) $)^{12}$, avaliando a incidência de hipotireoidismo em alunos frequentadores da APAE de Cascavel - Paraná, constataram que 11, dos 59 alunos que completaram a investigação clínico-laboratorial, apresentaram doença tireoidiana, sendo um com diagnóstico firmado de
SCdL, mostrando existir uma relação próxima dos distúrbios tireoidianos com as anomaliadas genéticas, a exemplo da SCdL.

Alguns genes e fenótipos proteicos responsáveis pela suscetibilidade para doenças tireoidianas autoimunes podem ser encontrados: CD40, CTLA-4, Tireoglobulina, Receptor de TSH, e PTPN22. Dois novos locus já foram identificados: locus RNASET2-FGFR1OP-CCR6 da região do cromossoma $6 q 27$ e uma região intergênica do cromossoma 4p1413. Com relação à síndrome de Cornélia de Lange, há também alguns achados: ela é causada por mutações no gene NIPBL em $65 \%$ dos pacientes, sendo menos frequente em indivíduos com mutações nos genes SMC1A e HDAC8, e raramente nas mutações SMC3 e RAD21. O gene de NIPBL regula proteínas do complexo de coesina, acarretando disfunção predominantemente no processo de replicação e ativação linfocitária, mostrando alterações em linfócitos $\mathrm{T}$ e $\mathrm{B}$ na $\mathrm{SCdL}$ - enquanto os genes SMC1A e SMC3 produzem partes estruturais desta proteína14. Diante do exposto, em relação à base genética, cromossômica e molecular, não há qualquer tipo de evidência que aponte intercessão fidedigna entre SCdL e Doença de Graves.

Em referência a esta última, a produção de autoanticorpos pelos linfócitos B é de suma importância na sua patogênese. Infiltrados linfocitários no tecido tireoidiano e retro-orbitário em pacientes com tal doença formam folículos linfoides secundários, contendo linfócitos B e T15. Dessa forma, a Doença de Graves é atualmente considerada como uma entidade autoimune mediada pela ativação dos dois principais tipos de células linfocitárias existentes.

Pode-se pressupor que exista uma interposição de base imunológica e fisiopatológica em ambas as patologias já que diferentes mecanismos cromossômicos e moleculares estão implicados na gênese fenotípica da SCdL e nas alterações tireoidianas da Doença de Graves.

Diante do exposto, nota-se uma relação bem próxima entre desordens metabólicas e tireoidianas com síndromes genéticas, incluindo a Síndrome de Cornélia de Lange. É importante que a equipe multidisciplinar tenha essa percepção, já que a piora clínica desses pacientes pode ter, como circunstância, uma desordem endócrina. Assim, uma simples correção hormonal pode aliviar sua sintomatologia, acarretando melhora da qualidade de vida.

\section{REFERENCIAS}

1. Ferrari MG, Castro MGL. As crianças com síndrome de Cornélia de Lange na escola comum: desafios e superação a partir de relatos familiares. Pró-discente: Caderno de Prod. Acad. -Cient. 2012 Jan-Jun;18(1):7-17.

2 Deardorff MA, Noon SE, Krantz ID. Cornelia de Lange syndrome. In: Adam MP, editor. Gene Reviews [Internet]. Washigton; 2007 [acesso 2017 Jan 02] Disponível em: https://www.ncbi.nlm.nih.gov/books/NBK1104/.

3 Oliver C, Arron K, Sloneem J, Hall S. Behavioural phenotype of Cornelia de Lange syndrome: case-control study. Br J Psychiatry. 2008 Dec; 193(6): 466-70. doi: 10.1192/bjp.bp.107.044370.

4 Rajan R, Benke JR, Kline AD, Levy HP, Kimball A; Mettel TL; et al. Insomnia in cornelia de lange syndrome. Int J Pediatr Otorhinolaryngol 2012 Jul: 76(7): 972-
5. doi: 10.1016/j.ijporl.2012.03.008.

5 Barroso CF, Santos AF, Pessoa PP, Pires LV, Castro LM, Pimentel A, et al. Estado nutricional relativo ao zinco em pacientes com hipertireoidismo. Nutrire. 2012; 37(supl): 27-33.

6 Zimmermann MB, Boelaert K. lodine deficiency and thyroid disorders. Lancet Diabetes Endocrinol. 2015 Apr; 3(4):286-95. doi: 10.1016/S22138587(14)70225-6.

7 Limbach M, Saare M, Tserel L, Kisand K, Eglit T, Sauer S, et al. Epigenetic profiling in $\mathrm{CD} 4+$ and $\mathrm{CD} 8+\mathrm{T}$ cells from Graves' disease patients reveals changes in genes associated with T cell receptor signaling. J Autoimmun 2016 Fev; 67: 
46-56. doi: 10.1016/j.jaut.2015.09.006.

8 Ellaithi M, Gisselsson D, Nilsson T, Elagib A, FadlElmula I, Abdelgadir M. A case of Cornelia de Lange syndrome from Sudan. BMC Pediatr. 2007; 7:6. doi: 10.1186/1471-2431-7-6.

9 Mikołajewska E. Interdisciplinary therapy in cornelia de lange syndrome review of the literature. Adv Clin Exp Med. 2013 Jul-Aug; 22(4): 571-7. PubMed PMID: 23986218.

10 Montes ML, Saldarriaga W, Isaza C. Description of a case of Cornelia de Lange syndrome: Contribution to better ante-natal and post-natal diagnoses. Colomb Med. 2006 Oct-Dez; 37(4): 323-7.

11 Nisihara RM, Utiyama SRR, Fiedler PT, Oliveira NP, Kotze LMS, Reason, LM. Alterações do TSH em pacientes com síndrome de Down: uma interpretação nem sempre fácil. J. Bras. Patol. Med. Lab. 2006 Out; 42(5): 339-343. doi: http://
dx.doi.org/10.1590/S1676-24442006000500005.

12 Silva AB, Sandrini F. Avaliação da incidência de hipotireoidismo em alunos frequentadores da apae de cascavel. Revista Thêma et Scientia. 2013 Jul-Dez ; $3(2): 85-88$

13 Chu X, Pan CM, Zhao SX, Liang J, Gao GQ, Zhang XM, et al. A genome-wide association study identifies two new risk loci for Graves' disease. Nat Genet. 2011 Aug; 43(9):897-901. doi: 10.1038/ng.898.

14 Feng L, Zhou D, Zhang Z, Liu Y, Yang Y. Exome sequencing identifies a de novo mutation in HDAC8 associated with Cornelia de Lange syndrome. J Hum Genet. 2014 Sep; 59(9):536-539. doi: 10.1038/jhg.2014.60.

15 Klecha AJ, Barreiro Arcos ML, Frick L, Genaro AM, Cremaschi G. Immune-endocrine interactions in autoimmune thyroid diseases. Neuroimmunomodulation 2008; 15(1): 68-75. doi: 10.1159/000135626.

\section{Como citar este artigo/How to cite this article:}

Ferreira TCP, Rebelo AAF, Kahwage AM, Guimarães ROB. Síndrome de Cornélia de Lange e Doença de Graves: uma associação rara J Health Biol Sci. 2018 Abr-Jun; 6(2):206-210 